http://dx.doi.org/10.32929/2446-8355.2018v27n4p471-481

\title{
PLANTAS DE COBERTURA E MANEJO DE ALÉIAS NO PLANTIO DIRETO DE BRÓCOLIS
}

\author{
Cristina Maria de Castro ${ }^{1 *}$, Antonio Carlos Pries Devide ${ }^{2}$
}

\begin{abstract}
${ }^{1}$ Pesquisador Científico, Doutora em Ciência do Solo, APTA Polo Regional Vale do Paraíba, Pindamonhangaba, SP. *E- mail:cristinacastro@apta.sp.gov.br.

${ }^{2}$ Pesquisador Científico, Doutor em Fitotecnia, APTA Polo Regional Vale do Paraíba, Pindamonhangaba, SP.
\end{abstract}

Recebido: 09/02/2018; Aceito: 11/12/2018

RESUMO: O plantio direto de brócolis de cabeça única no inverno, sobre diferentes culturas de cobertura, implantadas em sistema de aléias de guandu, em rotação com milho verde no verão, sob manejo orgânico, foi objetivo deste estudo. O delineamento foi em blocos ao acaso, em parcelas sub-divididas em faixas, com dois pré-cultivos: Sorghum bicolor e consórcio (sorgo + Crotalaria juncea); faixas separadas pelas aléias (Cajanus cajan). O consórcio aportou maior biomassa $\left(64,8 \mathrm{t} \mathrm{ha}^{-1}\right.$ e 21,3 $\mathrm{t} \mathrm{ha}^{-1} ; 49,2 \mathrm{t} \mathrm{ha}^{-1}$ e $\left.14,9 \mathrm{t} \mathrm{ha}^{-1}\right)$ que o sorgo (51,9 t ha $\mathrm{ta}^{-1}$ e $18,0 \mathrm{t} \mathrm{ha}^{-1} ; 40,5$ e $12,5 \mathrm{t} \mathrm{ha}^{-1}$ matéria fresca e matéria seca) nos $1^{\circ}$ e $2^{\circ}$ ano (2013/2014). A produção de brócolis na palha do sorgo com poda do guandu foi de 7,81 t $\mathrm{ha}^{-1}$ e 4,72 $\mathrm{t} \mathrm{ha}^{-1}$, e sem poda $6,55 \mathrm{t} \mathrm{ha}^{-1}$ e $3,17 \mathrm{t} \mathrm{ha}^{-1}$; na palha do coquetel foi maior, sendo com poda do guandu de $9,86 \mathrm{t} \mathrm{ha}^{-1}$ e $6,12 \mathrm{t} \mathrm{ha}^{-1}$, e sem poda $8,46 \mathrm{t} \mathrm{ha}^{-1}$ e 4,46 $\mathrm{t} \mathrm{ha} \mathrm{h}^{-1}$ (2013/2014). O aporte de material orgânico oriundo dos resíduos das culturas anuais forneceu um total de 24,43 t ha-1 matéria seca (resíduos brócolis e milho verde + vegetação espontânea) no sistema produtivo. Das aléias de guandu que não foram podadas, colheu-se $581 \mathrm{~kg} \mathrm{ha}^{-1} \mathrm{de}$ feijão guandu seco e beneficiado. O emprego de adubos verdes em pré-cultivo, aliado a aleias de guandu, no plantio direto orgânico de brócolis rotacionado com milho-verde, melhora a fertilidade do solo e mantém a sustentabilidade do sistema de produção agroecológico.

Palavras-chave: Brassica oleraceae. Adubo verde. Agricultura orgânica.

\section{COVER CROPS AND MANAGEMENT OF ALLEY CROPING UNDER NO TILLAGE SYSTEM BROCCOLI PLANTS.}

\begin{abstract}
No-tillage under organic management of single head of broccoli in the winter, cultivated in hedgerows of pigeon pea, in alley cropping system, in rotation with corn in the summer, was aim of this study. The experimental is a randomized block in split plot design and six replicates in the plot scheme sub-divided into rows with Sorghum and mix (C. juncea + S. bicolor. The mix contributed higher biomass $\left(64.8 \mathrm{t} \mathrm{ha}^{-1}\right.$ and $21.3 \mathrm{t} \mathrm{ha}^{-1}, 49.2 \mathrm{tha}^{-1}$ and $14.9 \mathrm{t} \mathrm{ha}^{-1}$ ) than sorghum (51.9 $\mathrm{t} \mathrm{ha}^{-1}$ and $18.0 \mathrm{t} \mathrm{ha}^{-1}, 40.5$ and $12.5 \mathrm{t} \mathrm{ha}^{-1}$ fresh and dry matter) in the 1st and 2nd year (2013/2014). The production of broccoli in straw sorghum with pruning of pigeon pea was 7,81 tha- $\mathrm{th}^{-1}$ and 4,72 $\mathrm{tha}^{-1}$ and without pruning 6,55 $\mathrm{t} \mathrm{ha}^{-1}$ and $3,17 \mathrm{t} \mathrm{ha}^{-1}$; in mix straw was with pruning pigeon pea of $9,86 \mathrm{t} \mathrm{ha}^{-1}$ and $6,12 \mathrm{t} \mathrm{ha}^{-1}$ and without pruning 8,46 tha-1 and 4,46 $\mathrm{t} \mathrm{ha}^{-1}$ (2013/2014). The contribution of organic matter from annual crop residues provided a total of $24.43 \mathrm{t} \mathrm{ha}^{-1}$ dry matter (residues of broccoli and green
\end{abstract}


corn + spontaneous vegetation) in the production system. Production of pigeon pea which were not pruned $581 \mathrm{~kg} \mathrm{ha}^{-1}$ of harveste and benefited. The use of green manures in precultivation, together with hedgerows of pigeon pea, under no tillage organic of broccoli rotated with green maize improves soil fertility and maintains the sustainability of the agroecological production system.

Key words: Brassica oleraceae. Green manure. Organic agriculture.

\section{INTRODUÇÃO}

Sistemas agroecológicos de produção são mais resilientes às adversidades climáticas, sendo intimamente relacionado com o nível de biodiversidade das áreas agrícolas. Promover a agrobiodiversidade e a sustentabilidade, por meio do acúmulo de matéria orgânica e do aumento da diversidade de espécies, requer práticas de manejo que favoreçam os processos naturais e interações biológicas no agroecossistema (FUNES-MONZOTE e SERRANO, 2016). Práticas como o plantio direto, e o uso de aléias com leguminosas, promovem mudança no redesenho de monocultivos de hortaliças, elevam os teores de matéria orgânica do solo, reduzindo a necessidade da fertilização com nitrogênio externo e melhorando a liberação de nutrientes para as culturas e trazem benefícios duradouros ao sistema produtivo (NICHOLLS et al., 2015; ALTIERI e NICHOLLS, 2013).

O emprego dos adubos verdes ajuda a manter a sustentabilidade dos sistemas agroecológicos (ALTIERI et al., 2003; SANTOS, 2002; GLEISSMAN, 2001), principalmente no cultivo de hortaliças, onde da mecanização com enxada rotativa mobiliza excessivamente o solo, mineralizando a matéria orgânica. Na horticultura, o ciclo curto das espécies, geralmente exigentes em nutrientes, demanda alternativas para o aporte de nitrogênio. $\mathrm{O}$ plantio direto sem dessecantes é uma prática sustentável, aporta matéria orgânica, mantêm a umidade e protege a biota do solo, reduzindo a necessidade de mão de obra com capinas.

A adubação verde traz inúmeras vantagens ao horticultor, o uso das crotalárias (Crotalaria spp) são conhecidas por reduzir a população de nematoides do solo, além de adicionar nitrogênio ao sistema produtivo. De acordo com o mesmo autor, o uso de diferentes espécies de adubos verdes com sistema radicular mais profundos, auxiliam na ciclagem de nutrientes de horizontes do solo, favorecem a manutenção da matéria orgânica, diminuem a população de plantas infestantes, entre outros benefícios (TIVELLI et al., 2010).

O sistema de plantio direto em hortaliças encontra desafios a serem superados, visando aliar as características espaciais e temporais dos adubos verdes com a cultura comercial, a sincronização da demanda de nutrientes com o ciclo da cultura, maquinário adequado para pequenas áreas e a grande rotatividade que se encontra em uma área de produção de hortaliças devido ao ciclo curto. O autor afirma ainda, que muitos fatores a favor do plantio direto podem ser citados, como a mitigação processos erosivos causados pelo excessivo revolvimento do solo pelo uso da enxada rotativa, rotação de culturas com espécies mais ricas em carbono, como gramíneas, melhorando a fertilidade do solo, aumento da diversidade de inimigos naturais na área de cultivo, amenização dos picos de temperatura proporcionados pela cobertura do solo pela palhada, entre outros (MELO et al., 2010). 
A cultura do brócolis, Brassica oleracea var. italica, divide-se em dois grupos, ramoso e de cabeça única, chamado também de brócolis japonês, que vem se expandindo nos últimos anos, por apresentar características favoráveis ao congelamento, maior vida de prateleira por não amarelar e apresentar adequadas propriedades culinárias (FERREIRA et al., 2013). Pertencente à família Brassicaceae, exigente quanto à fertilidade do solo e micronutrientes, vem sido estudada em plantio direto, com boa produtividade (MELO et al., 2010, SILVA, 2002).

Estudos com bases científicas da adequação do manejo de adubos verdes para horticultura são demandas atuais. O objetivo dessa pesquisa foi reunir informações para adequar o manejo da adubação verde na cultura de brócolis de cabeça única no inverno, em sistema de aleias com guandu, em plantio direto orgânico sobre os resíduos dos pré-cultivos sorgo e coquetel (sorgo+crotalária), em rotação com milho verde no verão.

\section{MATERIAL E MÉTODOS / MATERIAL AND METHODS}

O experimento se desenvolveu no período de novembro/2012 a novembro/2014, no Setor de Fitotecnia do Polo Regional do Vale do Paraíba/APTA/SAA em Pindamonhangaba/SP, em solo classificado como Latossolo Vermelho amarelo, A moderado, com textura franco-argilosa. O clima da região é o Cwa -quente com inverno seco, conforme a classificação de Köppen. Os dados climatológicos no período da condução do experimento constam na Figura 1.

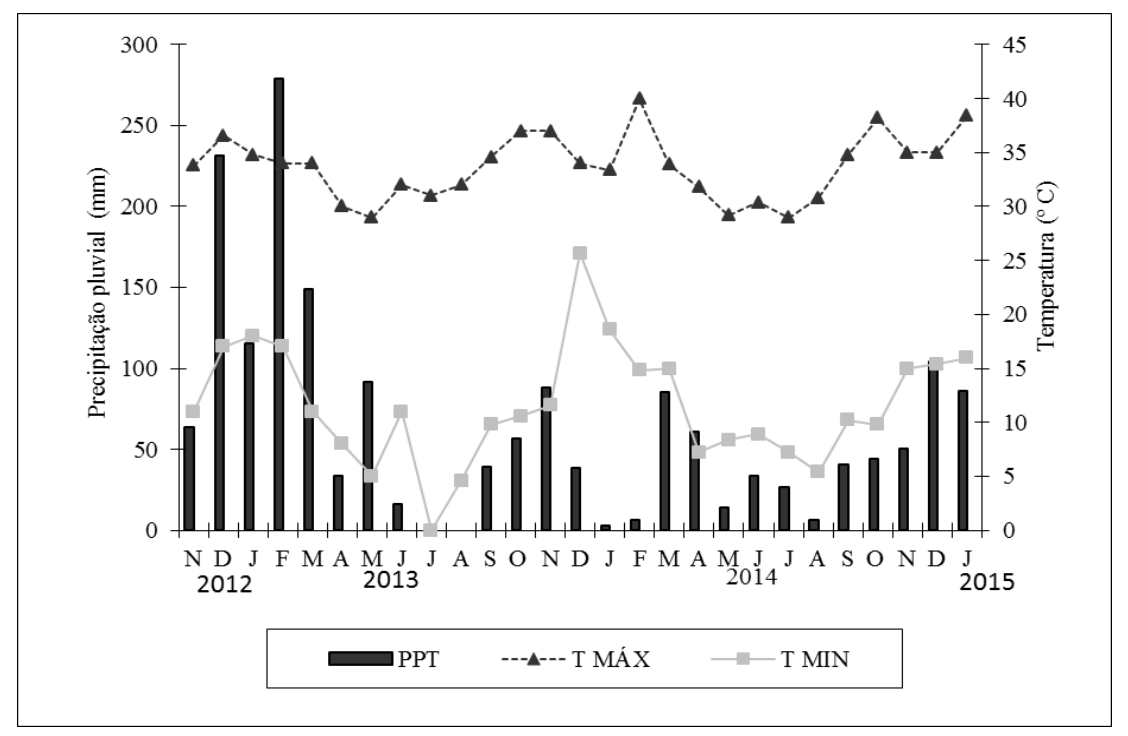

Figura 1. Médias de precipitação pluvial, temperaturas mínima e máxima em Pindamonhangaba, SP, no período de novembro/2012 a Janeiro/2015. Averages of rainfall, minimum and maximum temperatures in Pindamonhangaba, SP, from November / 2012 to January /2015. (CIIAGRO, 2015)

O delineamento adotado foi em blocos ao acaso com quatro tratamentos: T1 - plantio direto brócolis na palha sorgo; T2 - plantio direto brócolis na palha sorgo + resíduos poda do guandu; T3 - plantio direto brócolis na palha consórcio (sorgo+crotalária); T4 - plantio direto brócolis na palha do consórcio (sorgo + crotalária) +resíduos poda do guandu; com seis repetições, no esquema de parcelas sub-divididas em faixas. Em novembro/2012 e 
novembro/2014 foram realizadas as coletas de solo nas profundidades de: $0-5 \mathrm{~cm} ; 5-10 \mathrm{~cm} \mathrm{e}$ 10-20 cm, determinando-se a fertilidade química do solo, o $\mathrm{N}$ total e o carbono orgânico. Em dezembro/2012 realizou-se calagem em área total de acordo com análise química, seguindo-se o preparo do solo com grade aradora e riscador. A área total experimental de $1800 \mathrm{~m}^{2}$ (30 x 60 $\mathrm{m}$ ), foi dividida em quatro faixas (= parcelas) de 10 x $30 \mathrm{~m}$, semeadas em dezembro/2012 com sorgo (Sorghum bicolor) e consórcio [sorgo+ crotalária (Crotalaria juncea)], nas densidades de $40 \mathrm{~kg} \mathrm{ha}^{-1}$ e $10 \mathrm{~kg} \mathrm{ha}^{-1}$ para crotalária e sorgo, respectivamente; faixas essas separadas por fileiras duplas de Cajanus cajan cv. Mandarim (guandu), espaçadas $50 \mathrm{~cm}$ entre si, na densidade de 15 sementes por metro linear. As sub-parcelas receberam os resíduos da poda do guandu, realizada em toda sua extensão (10 metros de comprimento), a 1 metro de altura; por ocasião da roçada dos adubos verdes para o plantio direto do brócolis no inverno. Já nas sub-parcelas, onde o guandu não foi podado, foi determinado a produção de grãos do feijão guandu, no segundo ano (2014), colhendo-se vagens nas plantas em cinco metros lineares, com três repetições, avaliando-se após beneficiamento, a produção comercial de grãos do feijão guandu.

As espécies crotalária (cv. IAC resistente a Macrophomina) $C$. junceae e sorgo $S$. bicolor (cv. BRS 610) foram selecionadas pela tolerância a solos de baixa fertilidade, boa produtividade, excelente sanidade foliar (sorgo), fixação biológica de nitrogênio (crotalária), rápido crescimento, sistema radicular profundo e alta capacidade de extração e reciclagem de nutrientes. (CALEGARI et al., 1992). O consórcio das duas espécies foi previsto em busca da mistura de características das plantas que resulte, além da rápida cobertura do solo, em uma adequada taxa de liberação de nutrientes. Nas condições tropicais, a mineralização da matéria orgânica das leguminosas é intensa em função da baixa relação $\mathrm{C} / \mathrm{N}$, possivelmente, resultando na perda de $\mathrm{N}$ por diversas formas e consequente exposição do solo precocemente. O feijão guandu encontra-se distribuído em toda a região Central, Norte e Nordeste do Brasil; situa-se entre as mais importantes leguminosas alimentares, capaz de produzir colheitas elevadas de grãos ricos em proteína mesmo em solos de baixa fertilidade natural, adaptado a altas temperaturas e à seca, de porte arbustivo e semi-perene, além do uso como quebraventos, seus grãos verdes e secos são utilizados no consumo humano e animal (AZEVEDO et al., 2007).

As mudas de brócolis, híbrido AVENGER, foram produzidas em bandejas de 200 células de isopor em substrato orgânico produzido localmente, a base de $70 \%$ composto peneirado (feito à base de capim napier e esterco bovino fresco) $30 \%$ terra e $10 \mathrm{~g} / \mathrm{l}$ de termofosfato magnesiano $\left(17,5 \% \mathrm{P}_{2} \mathrm{O}_{5}\right.$ Total, $18 \% \mathrm{Ca}, 7 \% \mathrm{Mg}, 0,10 \% \mathrm{~B}, 0,05 \% \mathrm{Cu}, 0,30 \%$ Mn, 10,0 \% SI, 0,55\% Zn), nos dois anos de plantio (2013 e 2014); pulverizadas 15 dias após emergência e 15 dias após transplante das mudas para o campo com solução de molibdato de sódio e ácido bórico ( 1 e 3 g/litro respectivamente). O plantio manual foi realizado após a roçada dos adubos verdes, (abril de cada ano), em covas adubadas com composto, feito à base de capim napier e esterco bovino fresco ( 2 litros/cova) e $90 \mathrm{~kg} / \mathrm{ha} \mathrm{N}$ (farelo de mamona), 224 $\mathrm{kg} / \mathrm{ha} \mathrm{P}_{2} \mathrm{O}_{5}$ (farinha de ossos), $96 \mathrm{~kg} / \mathrm{ha}$ de $\mathrm{K}_{2} \mathrm{O}$ (sulfato de potássio); e em cobertura (30 DAP): $270 \mathrm{~kg} / \mathrm{ha} \mathrm{N}$ (farelo de mamona).

O espaçamento utilizado foi $1,0 \times 0,5 \mathrm{~m}$, sendo 50 plantas por parcela, com área útil de 10 plantas. Os tratos fitossanitários foram: controle de formiga cortadeira (somente nas três 
primeiras semanas) com isca Mirex-S; e controle de lagarta com Dipel (Bacillus thuringiensis), quando necessário. A colheita foi realizada em junho/julho de cada ano, sendo determinada a produtividade comercial.

Após o término da colheita do brócolis, em agosto/setembro de cada ano, foi semeado milho doce, variedade Eldorado, em covas abertas diretamente entre os resíduos culturais do brócolis e da vegetação espontânea, no espaçamento $1,0 \times 0,20 \mathrm{~m}$ entre as plantas. A adubação realizada conforme BOLETIM $200 \mathrm{IAC}$, com $20 \mathrm{Kg} \mathrm{N}, 100 \mathrm{Kg} \mathrm{P}_{2} \mathrm{O}_{5}, 50 \mathrm{Kg}$ de $\mathrm{K}_{2} \mathrm{O}$ por ha, e em cobertura aos 30 dias após plantio com $50 \mathrm{~kg} \mathrm{~N}$ e $30 \mathrm{Kg} \mathrm{K}_{2} \mathrm{O}$ ha. Os adubos utilizados foram esterco bovino curtido, farinha de osso e sulfato de potássio no plantio, e em cobertura torta de mamona. Os tratos culturais realizados foram capinas e pulverizações quinzenais com Dipel para controle da lagarta do cartucho. A irrigação foi realizada por aspersão convencional com frequência de três vezes por semana. A colheita do milho foi realizada em nov-dez de cada ano, avaliando-se a produtividade nos diferentes tratamentos.

No $2^{\circ}$ ano de plantio da cultura do brócolis, foi realizado somente o sulcamento por sob os resíduos da cultura do milho para plantio dos pré-cultivos (sorgo e coquetel), com os mesmos espaçamentos e densidades do ano anterior.

A massa fresca (MF) e seca (MS) das culturas de cobertura foram determinadas por meio da coleta de plantas presentes em uma área de três metros lineares de cada parcela. Após a pesagem, sub-amostras de $500 \mathrm{~g}$ foram acondicionadas em sacos de papel e dispostas em estufa com ventilação de ar forçada regulada a temperatura de $65^{\circ} \mathrm{C}$ até peso constante, para aferição de massa seca e determinação do teor de N (BREMER e MULVANEY, 1982), P, K, $\mathrm{Ca}$ e Mg (BATAGLIA et al., 1983). Os dados originais foram submetidos à análise de variância ao nível de 5\% de probabilidade e as médias foram comparadas entre si, pelo teste Tukey, utilizando o Software Sisvar (FERREIRA, 2011).

\section{RESULTADOS E DISCUSSÃO}

Os adubos verdes apresentaram excelente desenvolvimento e acúmulo de biomassa, com valores de 18,0 t.ha' ${ }^{-1} / \mathrm{MS}$ e 21,3 t.ha-1/MS no ano de 2013 e 12,5 t.ha-1/MS e 14,9 t.ha 1/MS no ano de 2014 para sorgo e consórcio (sorgo + crotalária), respectivamente. O desenvolvimento das plantas foi avaliado através da produção de biomassa e também pela avaliação da altura das plantas, sendo que o consórcio propiciou um maior aporte de biomassa nos dois anos, provavelmente, a presença da leguminosa crotalária, aliada à associação com bactérias fixadoras de N. No segundo ano (2014), devido a estiagem e forte calor (Fig.1), houve menor aporte de biomassa de ambas plantas de cobertura. Em abril/2014, por ocasião do corte, as plantas estavam com alturas de 3,30 m, 2,13 m e 2,66 m para guandu, sorgo e coquetel, respectivamente.

O guandu, plantado somente em fileira dupla, para separar as faixas de pré-cultivos e redesenhar a paisagem, proporcionou bom aporte de biomassa ao sistema; podado a um metro de altura, forneceu em 2013, 6,6 $\mathrm{tha}^{-1}$ e 2,4 $\mathrm{t} \mathrm{ha}^{-1}$ de MF e MS respectivamente, que foram dispostos na área logo após o transplante do brócolis. No segundo ano (2014), comprovando sua rusticidade, mesmo com a seca, a rebrota do guandu proporcionou maior aporte do que 
ano anterior, fornecendo 8,5 $\mathrm{t} \mathrm{ha}^{-1}$ e 4,5 $\mathrm{t} \mathrm{ha}^{-1}$ de MF e MS. Oliveira et al. (2006), na região serrana do estado do Rio de Janeiro, com o cultivo em sistema orgânico de inhame (Colocasia esculenta) em aléias de guandu, no mesmo sistema de fileiras duplas, encontrou, aporte de 6,58 $\mathrm{t} \mathrm{ha}^{-1}$ de biomassa seca, inserindo no sistema produtivo $159 \mathrm{~kg} \mathrm{ha}^{-1} \mathrm{de} \mathrm{N} \mathrm{e}$ ainda a ciclagem de $20 \mathrm{~kg} \mathrm{ha}^{-1} \mathrm{de} \mathrm{P}, 136 \mathrm{~kg} \mathrm{ha}^{-1} \mathrm{de} \mathrm{K}, 64 \mathrm{~kg} \mathrm{ha}^{-1} \mathrm{de}$ Ca e $16 \mathrm{~kg} \mathrm{ha}^{-1} \mathrm{de} \mathrm{Mg}$.

A cultura do brócolis apresentou excelente desenvolvimento, com colheita em julho e agosto, obtendo-se produtividade satisfatória (Tabela 1) e excelente padrão comercial. A produtividade normal chega a 10.000 a 13.000 maços por hectare do tipo ramoso, e do tipo inflorescência única podem se colher até mais de 25.000 plantas por hectare, dependendo do espaçamento utilizado (FAHL et al., 1998).

Arruda Junior et al. (2015), conduziu estudo em Registro, SP, no inverno, avaliando efeito espaçamento e cultivo adensado de brócolis de cabeça única, encontrando para o hibrido Avenger valores próximos aos encontrados neste estudo, com peso médio de inflorescência de 365,62 $\mathrm{g}$ no espaçamento $0,8 \times 0,4 \mathrm{~m}$ e produtividade de $8,57 \mathrm{t} \mathrm{ha}^{-1}$.

Tabela 1. Produção comercial e peso médio cabeça de brócolis no manejo orgânico (2013/2014). Commercial production and average broccoli head weight in organic management (2013/2014).

\begin{tabular}{|c|c|c|}
\hline \multicolumn{3}{|c|}{2013} \\
\hline & Com poda do guandu & Sem poda do guandu \\
\hline & \multicolumn{2}{|c|}{ Produção comercial $\left(\mathrm{t} \mathrm{ha}^{-1}\right)$} \\
\hline Sorgo & $7,81 *$ a $\mathrm{A}$ & 6,55 a $\mathrm{A}$ \\
\hline \multirow[t]{2}{*}{ Coquetel } & 9,86 b B & 8,46 b B \\
\hline & \multicolumn{2}{|c|}{ Peso médio cabeça $(\mathrm{g})$} \\
\hline Sorgo & 390,88 a A & 327,44 a A \\
\hline Coquetel & $493,11 \mathrm{~b} \mathrm{~B}$ & $422,89 \mathrm{~b} \mathrm{~B}$ \\
\hline \multicolumn{3}{|c|}{2014} \\
\hline & \multicolumn{2}{|c|}{ Produção comercial (t.ha $\left.{ }^{-1}\right)$} \\
\hline Sorgo & $4,72 *$ a $\mathrm{A}$ & 3,17 a B \\
\hline \multirow[t]{2}{*}{ Coquetel } & 6,12 b A & 4,46 a B \\
\hline & \multicolumn{2}{|c|}{ Peso médio cabeça $(\mathrm{g})$} \\
\hline Sorgo & 230,00 a $\mathrm{A}$ & 156,67 a B \\
\hline Coquetel & $306,67 \mathrm{~b} \mathrm{~A}$ & 221,67 b B \\
\hline
\end{tabular}

Seabra Junior et al. (2014), em estudo com competição de cultivares de brócolis de cabeça única, em sistema convencional de cultivo, e plantio adensado, utilizando também híbrido Avenger, aferiram massa fresca da inflorescência com $886 \mathrm{~g} / \mathrm{planta}$, enquanto que Ohse et al. (2012) obtiveram 968 g/planta, tanto plantada em consórcio com alface, quanto plantada em monocultivo. Já Melo et al. (2010), também com híbrido Avenger, obtiveram massa fresca da inflorescência de $458 \mathrm{~g} /$ planta e produtividade de $13,2 \mathrm{t}^{\text {ha }}{ }^{-1}$ em plantio 
direto na palhada de milheto, no verão, em Brasília/DF, porém, com adubação convencional e irrigação diária.

Dentre os benefícios da mistura da gramínea com a leguminosa, a rápida cobertura do solo e adequada taxa de liberação de nutrientes, favoreceram positivamente a produtividade comercial de brócolis. O tratamento que recebeu a poda das aléias de guandu, refletiu em maior peso médio da cabeça de brócolis. Silva (2002), em estudo de campo visando melhor adubação verde como cultura de cobertura, no plantio direto de brócolis de cabeça única sob manejo orgânico, verificou beneficio e melhoria na produção do brócolis de 18\%, introduzindo espécie crotalária em consorcio com sorgo.

Em plantios de brócolis no sistema convencional, sem ser em plantio direto, a irrigação via de regra é realizada diariamente; neste plantio, obteve-se maior eficiência no uso da água, pois os adubos verdes após roçados mantiveram o solo coberto com a palhada, protegendo o solo, diminuindo a temperatura e mantendo umidade por mais tempo, sendo a irrigação realizada somente três vezes por semana.

No segundo ano experimental (2014), as condições ambientais diferiram do ano de 2013; a queda de produtividade deve-se às adversidades climáticas já citadas. Porém, repetiuse o resultado, nas faixas onde o brócolis foi cultivado sob o consórcio de sorgo + crotalária, obteve-se maior produtividade e tamanho médio das cabeças. Também, foi significativa a diferença no tratamento com e sem poda das aleias do guandu, refletindo em maior produção e peso médio da cabeça de brócolis no tratamento com poda (Tabela 1.)

A cultura do milho verde apresentou baixa produtividade (Tabela 2), apesar de ter sido utilizada variedade Eldorado, selecionada em condições edafoclimáticas adversas, de baixa disponibilidade de N, com clima quente e seco na Baixada Metropolitana do Estado do Rio de Janeiro (MACHADO et al., 2003). Segundo Albuquerque et al. (2008), a média brasileira de produção de milhos híbridos, situa-se entre 9.000 e $15.000 \mathrm{~kg} \cdot \mathrm{ha}^{-1}$ de espigas despalhadas.

Tabela 2. Número de espigas comerciais, produção total e produção comercial do milho verde Eldorado, cultivado no manejo orgânico (1 Ano/2013). Number of commercial ears, total production and commercial production of Eldorado green maize, cultivated in organic management (1st Year / 2013).

\begin{tabular}{|c|c|c|c|c|c|c|}
\hline $\begin{array}{l}\text { Tratamento } \\
\text { Pré-cultivo }\end{array}$ & \multicolumn{3}{|c|}{ Com Poda } & \multicolumn{3}{|c|}{ Sem poda } \\
\hline \multirow{2}{*}{ Pré-cultivo } & \multirow[b]{2}{*}{ Total } & Produção & \multirow{2}{*}{$\begin{array}{l}\text { N.espigas } \\
\text { comerciais }\end{array}$} & \multicolumn{2}{|c|}{ Produção } & \multirow{2}{*}{$\begin{array}{l}\text { N. espigas } \\
\text { comerciais }\end{array}$} \\
\hline & & Comercial & & Total & Comercial & \\
\hline \multirow[b]{2}{*}{ Sorgo } & & $\mathrm{tha}^{-1}$ & & & $\mathrm{tha}^{-1}$ & \\
\hline & $1630,9 \mathrm{aA}$ & $1339,3 \mathrm{aA}$ & $4544,2 \mathrm{aA}$ & $1264,8 \mathrm{aA}$ & $885,2 \mathrm{aB}$ & $3092,6 \mathrm{aB}$ \\
\hline Coquetel & $2394,4 \mathrm{bA}$ & $1890,9 \mathrm{bA}$ & $5870,4 \mathrm{aA}$ & $1840,7 \mathrm{bB}$ & $1419,8 \mathrm{bB}$ & $4250,0 \mathrm{bB}$ \\
\hline
\end{tabular}

*média de seis repetições; letras iguais minúsculas nas colunas e maiúsculas nas linhas não diferem entre si. (Tukey $\mathrm{p}<0,05)$. * averages of six replicates followed by the same letter, lowercase in the column and uppercase in the lines did not differ significantly from each other, Tukey, $p<0.05$.

Embora o sistema de produção orgânico não restrinja o uso de híbridos, o uso de variedades são preferidas; ensaios realizados pela Embrapa Milho e Sorgo (Cruz et al., 2009) tem demonstrado potencial produtivo e com características comerciais satisfatórias de 
variedades de milho, como alternativa viável para sistemas orgânicos de produção, de baixo custo, proporcionando maior autonomia do agricultor em produzir sua própria semente, além de obtenção de materiais genéticos regionalizados e adequados às características edafoclimáticas específicas. Esses autores, em ensaio conduzidos por três anos com 25 cultivares de milho em sistema orgânico de produção (2006 a 2009), constaram que variedades como CMS Caimbé (5,07 t ha $\left.{ }^{-1}\right)$, AL Piratininga (4,91 t ha $\left.{ }^{-1}\right)$, e Sintético 1X (4,91 $\left.\mathrm{t} \mathrm{ha} \mathrm{a}^{-1}\right)$, se destacaram com rendimentos iguais ao hibrido BRS $2020\left(4,95 \mathrm{t} \mathrm{ha}^{-1}\right)$ utilizado como testemunha.

A seca prolongada prejudicou a cultura do milho no segundo ciclo, não sendo computada a produtividade, porém com bom padrão comercial de espigas, suficiente para a manutenção da produção de semente variedade e o aporte de matéria orgânica ao sistema.

Foram determinadas a quantidade de material vegetal provenientes dos resíduos das culturas anuais e vegetação espontânea durante os dois anos de avaliação, que foram incorporados ao solo, visando melhoria da fertilidade do solo no sistema produtivo. No total foi computado um total de 24,43 $\mathrm{t} \mathrm{ha}^{-1} / \mathrm{MS}$, sendo: $0,87 \mathrm{tha} \mathrm{a}^{-1}+0,86 \mathrm{t} \mathrm{ha}^{-1}$ (total de resíduos da cultura do brócolis + vegetação espontânea, $1^{\circ}$ e $2^{\circ}$ ano) e $8,4 \mathrm{t} \mathrm{ha}{ }^{-1}+14,3 \mathrm{t} \mathrm{ha}{ }^{-1}$ (total de resíduos da cultura do milho + vegetação espontânea, $1^{\circ}$ e $2^{\circ}$ ano).

De maneira geral, houve melhoria na fertilidade do solo, nesses dois anos de plantio direto de brócolis em rotação ao milho verde, sob manejo orgânico; o teor de matéria orgânica aumentou passando de $26,5 \mathrm{~g} / \mathrm{dm}^{3}$ para $30 \mathrm{~g} / \mathrm{dm}^{3}(0-5 \mathrm{~cm})$ e $25 \mathrm{~g} / \mathrm{dm}^{3}$ para $27,5 \mathrm{~g} / \mathrm{dm}^{3}(5-$ $10 \mathrm{~cm}$ ) na faixa cultivada com sorgo; $26 \mathrm{~g} / \mathrm{dm}^{3}$ para $29,5 \mathrm{~g} / \mathrm{dm}^{3}(0-5 \mathrm{~cm})$ e $24,5 \mathrm{~g} / \mathrm{dm}^{3}$ para $29,5 \mathrm{~g} / \mathrm{dm}^{3}$ (5-10) na faixa com coquetel; valores considerados de médio a alto (Tomé $\mathrm{Jr}$, 1997). O valor mais elevado no pré-cultivo consórcio (sorgo + crotalária), provavelmente se deve a adição ao sistema da crotalária, que mesmo sendo leguminosa, possui alto teor de fibras, sendo sua decomposição mais lenta, permanecendo no sistema por mais tempo. Segundo Mielniczuk (1999), para avaliação da qualidade da adubação e consequente aporte de N, o teor de matéria orgânica é o indicador mais sensível, principalmente em regiões tropicais e subtropicais, onde os processos físicos, químicos e biológicos no solo são intensos. Ainda, Altieri e Nicholls (2013), relatam que solos com alto teor de matéria orgânica e alta atividade biológica, possuem boa fertilidade, bem como organismos benéficos abundantes que previnem doenças e pragas.

Como o guandu é uma fabaceae, reconhecida não somente por sua capacidade de produção de massa verde e fixação de N, mas, também, por seus grãos palatáveis verdes e maduros na culinária (AZEVEDO et al., 2007), visando agregar valor como renda complementar e fortalecer a segurança alimentar do próprio agricultor, avaliou-se nos tratamentos sem poda, no $2^{\circ}$ ano de implantação das aléias. A produção de grãos foi satisfatória, considerando que a produtividade média no Brasil, em condições ideais de cultivo em torno de 1,2 t.ha ${ }^{-1}$ grãos (FAHL et al., 1998), computando-se a média de $581 \mathrm{~kg} \mathrm{ha}^{-1}$ de feijão guandu seco e beneficiado. 


\section{CONCLUSÃO}

O emprego de adubos verdes em pré-cultivo no plantio direto orgânico de brócolis com aleias de guandu, e a rotação no verão com milho verde sob os resíduos culturais do brócolis, melhora a fertilidade do solo e mantém a sustentabilidade do sistema de produção agroecológico.

\section{AGRADECIMENTOS}

À Fundação de Amparo à Pesquisa do Estado de São Paulo (FAPESP) pelo apoio financeiro.

\section{REFERÊNCIAS BIBLIOGRÁFICAS / REFERENCES}

ALBUQUERQUE, C. J. B., VON PINHO, R. G.; SILVA, R. Produtividade de híbridos de milho verde experimentais e comerciais. Bioscience Journal, Darmstadt, v. 24, n. 2 , p.69-76, 2008.

ALTIERI, M.; NICHOLLS, D. Agroecologia y resiliencia al cambio climático, principios y consideraciones metodológicas. In: NICHOLLS C. ALTIERI, M. (Ed.). Agroecologia y Camio Climático: metodologias para evaluar la resiliencia socio-ecológica em comunidades rurales. Lima: Redagres Cyteg. Socla, 2013. p.7-20.

ALTIERI, M. A.; SILVA, E. N.; NICHOLLS, C. I. O papel da biodiversidade no manejo de pragas. Ribeirão Preto: Holos, 2003. 226 p.

ARRUDA JUNIOR, G.; VARGAS, P. F.; FERRARI, S.; PAVARINI, R. Desempenho de híbridos de brócolis de cabeça única em função de densidade e arranjo espacial. Nucleus, Havana, v. 12, n. 1, p.1999-2206, 2015.

AZEVEDO, R. L.; RIBEIRO, G. T.; AZEVEDO, C. L. L. Feijão Guandu: uma planta multiuso. Revista da Fapesp, São Paulo, v. 3, n. 2, p.81-86, 2007.

BATAGLIA, O.C.; FURLANI, A.M.C.; TEIXEIRA, J.P.F.; FURLANI, P.R.; GALLO, J.R. Métodos de análise química de plantas. Campinas: Instituto Agronômico, 1983. 48 p. (Boletim Técnico, 78).

BREMER, J. M.; MULVANEY, C. S. Nitrogen total. In: PAGE, AL. L.; MILLER, R. A.; KEENEY, D. R. (Eds). Methods of soil analysis. 2. ed. Madison: American Society of Agronomy, 1982. p. 595-624. (Agronomy, 9).

CALEGARI, A.; MONDARDO, A.; BULIZANI, E. A.; WILDNER, L. P.; COSTA, M. B. B.; ALCÂNTARA, P. B.; MIYASAKA, S.; AMADO, R. J. C. Adubação verde no sul do Brasil. Rio de Janeiro: AS-PTA, 1992. 346 p.

CRUZ, J. C.; PEREIRA FILHO, I. A.; OlIVEIRA, A. C.; GUIMARÃES, L. J. M.; QUERIROZ, L. R.; MATRANGOLO, W. J. R.; MOREIRA, J. A. A. Variedades de milho em sistema orgânico de produção. Sete Lagoas: Embrapa Milho e Sorgo, 2009. 6 p. (Comunicado Técnico, 171) 
FAHL, J.I.; CAMARGO, M. B. P.; PIZZINATTO, M. A.; BETTI, J.A.; MELO, A. M. T.; DE MARIA, I. C.; FURLANI, A. M. C. (Eds.). Instruções agrícolas para as principais culturas econômicas. 6. ed. rev. atualizada. Campinas: Instituto Agronômico, 1998. 213 p. (Boletim IAC, 200).

FERREIRA, S.; SOUZA, R. J.; GOMES, L. A. A. Produtividade de brócolis de verão com diferenes doses de bockashi. Revista Agrogeoambiental, Pouso Alegre, v. 5, n. 2, p.31-38, 2013.

FERREIRA, D. F. Sisvar: a computer statistical analysis system. Ciência \& Agrotecnologia, Lavras, v. 35, n. 6, p.1039-1042, 2011.

FUNES-MONZOTE, F.R.; SERRANO, M. M. Agroecologia: utopia para um sistema agroalimentario justo? Leisa, Revista de Agroecologia, Lima, v. 32, n. 3, p.9-12, 2016.

GLIESSMAN, S. R. Agroecologia: processos ecológicos em agricultura sustentável. 2. ed. Porto Alegre: UFRGS, 2001. 653 p.

MACHADO, A. T.; MACHADO, C. T. T.; MIRANDA, G. U.; COELHO, C. H. M.; GUIMARÃES, L. J. M. Respostas de variedades de milho a níveis e fontes de nitrogênio. Planaltina, DF: Embrapa Cerrados, 2003. 27 p. (Boletim de Pesquisa e Desenvolvimento)

MELO, R. A. C; MADEIRA, N. R.; PEIXOTO, J. R. Cultivo de brócolos de inflorescência única no verão em plantio direto. Horticultura Brasileira, Brasilia, v. 28, n. 1, p.23-28, 2010 .

MIELNICZUK, J. Matéria orgânica e a sustentabilidade de sistemas agrícolas. In: SANTOS, G. A.; CANARGIM, F. A. O. Fundamentos da matéria orgânica do solo: ecossistemas tropicais e subtropicais, 1999. cap. 1, p. 1-8.

NICHOLIS, C. I.; ALTIERI, M. A.; SALAZAR, A. H.; LANA, M. A. Agroecologia e o desenho de sistemas agrícolas resilientes às mudanças climáticas. Revista Agriculturas: experiências em agroecologia, Rio de Janeiro, n. 2, p.3-34, 2015.

OLIVEIRA, F. L.; GUERRA, J. G. M.; JUNQUEIRA, R. M.; SILVA, E. E.; OLIVEIRA, F. F.; ESPÍNDOLA, J. A. A.; ALMEIDA, D. L.; RIBEIRO, R. L. D.; URQUIAGA, S. C. Crescimento e produtividade do inhame cultivado entre faixas de guandu em sistema orgânico. Horticultura Brasileira, Brasília, v. 24, n. 1, p.53-58, 2006.

OHSE, S.; RESENDE, B. L. A.; SILVEIRA, L. S.; OTTO, R. F.; CORTEZ, M. G. Viabilidade agronômica de consórcios de brócolis e alface estabelecidos em diferentes épocas. Idesia, Arica, v. 30, n. 2, p.29-37, 2012.

SANTOS, L. G. C. Adubos verdes na horticultura orgânica. Agroecologia Hoje, Botucatu, v. 14, n. 2, p.22-23, 2002.

SEABRA JUNIOR, S.; NEVES, J. F.; DIAS, L.; SILVA, L. B.; NODARI, I. Produção de cultivares de brócolis de inflorescência única em condições de altas temperaturas. Horticultura Brasileira, Brasília, v. 32, n. 4, p.497-503, 2014. 
SILVA, V. V.. Effects of cover crop as green manure on Broccoli (Brassica oleraceae L. var. Italica Plenk) in no-tillage system. 2002. 102 f. Dissertação (Mestrado em Produção Vegetal) - Universidade Federal Rural do Rio de Janeiro, Seropédica, 2002.

TIVELli, S. W.; PURQUEIRO, L. F.; KANO, C. Adubação verde e plantio direto em hortaliças. Pesquisa \& Tecnologia, [S. 1.], v. 7, n. 1, p.1-8, 2010.

TOME JÚNIOR, J. B. Manual para interpretação de análise de solo. Guaíba: Agropecuária, 1997. 247 p. 